\title{
HIV-1 DNA in peripheral blood mononuclear cells is strongly associated with HIV-1 disease progression in recently infected West African adults
}

\section{In Press JAIDS 2008,}

\begin{abstract}
Albert Minga ${ }^{\mathrm{a}, \mathrm{b}}$, Xavier Anglaret ${ }^{\mathrm{a}, \mathrm{b}}$, Thomas-d'Aquin Toni ${ }^{\mathrm{a}}$, Marie-Laure Chaix ${ }^{\mathrm{c}}$, Lambert Dohoun $^{\text {a }}$, Yao Abo a , Ali Coulibaly ${ }^{\text {a }}$, Julien Duvignac ${ }^{\text {b }}$, Delphine Gabillard ${ }^{\text {b }}$, François Rouet ${ }^{\text {a }}$, Christine Rouzioux ${ }^{\mathrm{c}}$
\end{abstract}

\section{Affiliation :}

${ }^{a}$ Programme PAC-CI, Abidjan, Côte d'Ivoire.

${ }^{\mathrm{b}}$ INSERM, U897, Bordeaux, France.

${ }^{\text {c }}$ Service de Virologie, AP-HP Hôpital Necker, EA 3620 Université Paris-Descartes, Paris

\section{Correspondence :}

Dr Albert Minga

Programme PAC-CI

18 BP 1954

Abidjan 18

Côte d'Ivoire

Tel : +22521355278 or 07087661

Fax : +22521355995

e-mail: minga.albert@caramail.com 
Abstract (250 words)

Objective: To analyse the association between the HIV-1 DNA level in peripheral blood mononuclear cells (PBMCs) and disease progression in recently infected West-African adults.

Methods: HIV-1 DNA levels were measured in the PBMCs of 200 adults in the ANRS 1220 cohort who had recently been infected with HIV-1. The association between baseline HIV-1 DNA levels and disease progression was analyzed using multivariate Cox regression. Disease progression was defined as the occurrence of any of the following outcomes: death, first WHO stage 3-4 event or CD4 count $<200 / \mathrm{mm}^{3}$.

Results: 200 participants were followed for a median of 30 months. At baseline, the median time from HIV-1 seroconversion was 9 months, median $\mathrm{CD}^{+}$T-cell count was $471 / \mathrm{mm}^{3}$, median HIV-1 DNA level was $3.0 \log _{10}$ copies/10 $10^{6}$ PMCs and median plasma HIV-1 RNA level was 4.6 $\log _{10}$ copies $/ \mathrm{ml}$. The five-year probability of remaining free of any outcome was 0.74 (95\% CI $0.61-0.83)$ and 0.36 (95\% CI 0.23-0.49) in patients with baseline HIV-1 DNA $\leq 3.0$ and $>3.0$ $\log _{10}$ copies $/ 10^{6}$ PBMCs, respectively $(\mathrm{p}<0.001)$. The adjusted hazard ratio of disease progression was 2.17 in patients with HIV-1 DNA $>3.0 \log _{10}$ copies $/ 10^{6} \mathrm{PBMCs}$, compared to other patients (95\%CI 1.24-3.80, $\mathrm{p}=0.007)$. The only other factor associated with progression was follow-up CD4 count (hazard ratio $=1.23$ per 100 cells $/ \mathrm{mm}^{3}$ decrease; $95 \% \mathrm{CI} 1.07-1.41, \mathrm{p}=0.003$ ).

Discussion: PBMC HIV-1 DNA level was strongly associated with HIV-1 disease progression, even after adjusting for HIV-1 RNA and $\mathrm{CD}^{+}$T-cell count. Further studies should assess whether patients with high HIV-1 DNA levels should start antiretroviral therapy earlier than other patients.

Keywords: HIV-1 DNA ; seroconverters ; sub-Saharan Africa ; prognosis; markers 


\section{Introduction}

The $\mathrm{CD}^{+} \mathrm{T}$-cell count is the core marker of disease progression in human immunodeficiency virus type 1 (HIV-1) and is the key variable considered during the decision process for such major interventions as initiation of chemoprophylaxis to prevent opportunistic diseases or prescription of antiretroviral therapy (ART) (1). Another marker is the plasma HIV-1 RNA level, which can predict disease natural progression independently of $\mathrm{CD} 4{ }^{+} \mathrm{T}$-cell count (2) and is the key indicator used to evaluate the efficacy of ART in controlling viral replication $(3,4)$. Policy guidelines have long recommended routine monitoring of both $\mathrm{CD} 4^{+} \mathrm{T}$-cell counts and plasma HIV-1 RNA levels in HIV-infected patients on and off ART.

Since 2000, several studies have suggested that a third marker, the HIV-1 DNA level in peripheral blood mononuclear cells (PBMCs), may be strongly associated with disease progression, independently of plasma HIV-1 RNA level and CD4 ${ }^{+}$T-cell count (5-7). However, until now only a handful of cohort studies in Europe have demonstrated this association. In order for their findings to be convincing, they must prove replicable in diverse populations and settings.

We analyzed the association between HIV-1 DNA level in PBMCs and HIV-1 disease progression in a cohort of adults in Côte d'Ivoire, West Africa who were recruited shortly after their estimated date of HIV-1 seroconversion.

\section{Methods}

\section{Patients}

This study was conducted in the blood donor clinic of the blood bank of Abidjan, Côte d'Ivoire. In Côte d'Ivoire, blood donors are non-paid adult volunteers. Informed consent for HIV testing is obtained before each donation, and patients are notified that they have the option of receiving their test results at the blood donor clinic after a post-test counseling session.

Since June 1997, blood donors have been eligible to enroll in the ANRS 1220 Primo-CI cohort if they: (i) are diagnosed with HIV-1 or HIV-1/HIV-2 co-infection at blood donation; (ii) tested HIV-seronegative at the previous donation; (iii) return to the clinic for HIV test results; and (iv) are estimated to have serocoverted $<36$ months before the donation. We use the midpoint between the last negative and first positive HIV tests to estimate the date of seroconversion. All patients who accept to participate give written informed consent. The Primo-CI protocol was 
approved by the ethics committees of the national Ivorian program on AIDS and the institutional review board of the French Agency for Research on AIDS (ANRS, France).

For this study, we included in the analysis all participants in the Primo-CI cohort infected with HIV-1 alone, who entered the cohort between June 9, 1997 and February 1, 2006, and had a PBMC pellet cryopreserved at enrolment.

\section{Clinical follow-up}

The procedures of the Primo-CI cohort have been previously described $(8,9)$. In summary: Patients were examined by clinicians at enrolment and every 6 months thereafter. All subjects had free access to the study clinic at any time between scheduled visits. All clinical events were reviewed by an event documentation committee. The diagnostic criteria and treatment procedures were identical to those used for the Cotrame cohort, a cohort of HIV-infected adults followed up in Abidjan during the same period, under the supervision of the same team, and which procedure have been described elsewhere (10). Cotrimoxazole prophylaxis was systematically offered to all patients at enrolment (11). In February 2001, the blood donor clinic became a center for the UNAIDS/Côte d'Ivoire initiative for improving access to HIV drugs. From this date forward, ART was provided to all participants in the Primo-CI cohort who met WHO criteria for starting ART in resource-limited settings $(12,13)$. All drugs, clinical assessments, hospital stays and transport were offered free of charge.

\section{Clinical measurements}

HIV was diagnosed using two reactive enzyme-linked immunosorbent assays (ELISA) (Murex ICE 1-0-2, Abbott, North Chicago, IL, USA, and Vironostika HIV Uni-Form II, Organon Teknika BV, Boxtel, Netherlands). We confirmed HIV-1 infection before enrolling subjects, using two more ELISAs (Murex ICE 1-0-2 and Pepti-Lav 1-2, Pasteur Diagnostics, Marnes-laCoquette, France). Blood samples were collected at inclusion and every 6 months thereafter. Pellets of PBMCs were separated using a Ficol-Hypaque gradient and aliquots of plasma and PBMCs were stored in $-80^{\circ} \mathrm{C}$ freezers. $\mathrm{CD} 4^{+} \mathrm{T}$-cell counts were measured for each blood sample (FACScan, Becton Dickinson, Aalst-Erembodegem, Belgium). HIV-1 RNA plasma levels were measured in the CIRBA virology laboratory, in Abidjan (Cobas Amplicor HIV-1 Monitor, version 1.5, Roche Diagnostics Indianapolis IN, USA; threshold of detection 400 copies) and HIV-1 DNA levels were measured in the virology laboratory of the Necker Hospital, in Paris. We used a real time PCR assay to target the LTR gene region of HIV-1 DNA, as previously described (14). The standard curve consisting in five-fold dilutions of 8E5 cell total DNA 
(containing one copy of HIV-1 DNA per cell) was used. The cutoff of the assay was 6 copies/PCR, that is 40 copies $/ 10^{6}$ PBMCs. Total DNA in extracts was quantified using fluorescence readings at $260 \mathrm{~nm} ; 1$ microgramme of total DNA was considered to be equivalent to 150,00 cells. Results were expressed as the number of HIV-1 DNA copies per $10^{6}$ PBMCs.

\section{Statistical analysis}

Baseline data were defined as measurements taken on the date of inclusion in the cohort. Data were censored either at time of death or on December 31, 2006, for those patients who were still alive. For patients whose last contact with the study team was prior to December $31^{\text {st }} 2006$, we used tracing procedures up to June 30, 2007. Patients who were found alive or had died in 2007 were considered to be alive on December 31, 2006. The remaining patients were considered to be lost to follow-up and their data were censored at the date of their last contact with the study team. Finally, data on patients who started ART before December 31, 2006 but did not reach any disease progression outcome were censored at the date of ART initiation.

Spearman's correlation test was used to estimate the association between baseline HIV-1DNA, HIV-1RNA and CD4 ${ }^{+}$T-cell count. We considered three outcomes: death, first severe morbidity event, and first $\mathrm{CD} 4^{+}$T-cell count $<200 / \mathrm{mm}^{3}$. Severe morbidity events were defined as all WHO stage 3 or 4 events (12). We estimated the probability of remaining free of each outcome separately and all three outcomes combined using the Kaplan-Meier method. We analyzed the association of the baseline HIV-1 DNA level in PBMCs with each outcome and with at least one of the three outcomes, using multivariate Cox proportional hazard regression models. Baseline and follow-up CD4 count was included as a time-dependent variable. All other dependent variables were baseline variables associated with the outcome in univariate analysis $(p<0.25)$.

\section{Results}

Of the $254 \mathrm{HIV}-1$ positive patients included in the Primo-CI cohort during the study period, 200 patients had available baseline PBMC samples and were included in the study. Sixty-two percent of subjects were men, $65 \%$ were single, $53 \%$ had a steady source of income, and $75 \%$ had attained higher than primary school level education. Table 1 shows the other baseline characteristics of the cohort. The HIV-1 DNA level was found to be significantly correlated with baseline HIV-1 RNA level (Spearman test: $\mathrm{R}=0.48, \mathrm{p}<0.001$ ) and inversely correlated with baseline $\mathrm{CD}^{+} \mathrm{T}$-cell count (Spearman test: $\mathrm{R}=-0.44, \mathrm{p}<0.001$ ).

During follow-up, 10 patients died, 25 had at least one WHO stage 3 or 4 event, 41 had a CD $4^{+}$ T-cell count decline to $<200 / \mathrm{mm}^{3}$, and 57 had at least one of these three outcomes. In the 25 
patients with at least one stage 3 or 4 event, the first was either tuberculosis $(n=12)$, oral candidiasis $(n=7)$, or an invasive bacterial disease $(n=6)$.

During follow-up, 62 participants started ART, including 43 of the 100 (43\%) patients with baseline HIV-1 DNA $>3 \log _{10}$ copies $/ 10^{6}$ PBMCs and 19 of the 100 (19\%) patients with baseline HIV-1 DNA $\leq 3 \log _{10}$ copies $/ 10^{6}$. Among the 100 patients with baseline HIV-1 DNA $>3$ $\log _{10}$ copies $/ 10^{6}$ PBMCs, $20 \%$ started ART at $>200 \mathrm{CD} 4 / \mathrm{mm}^{3}$ and $24 \%$ started ART before being diagnosed with a WHO stage 3 or 4 clinical event. In the 100 patients with baseline HIV-1 DNA $\leq 3 \log _{10}$ copies $/ 10^{6}$, these percentages were $6 \%$ and $12 \%$, respectively.

Figure 1 shows the overall probability of remaining free of any outcome over time. The five-year probabilities of survival, of remaining free of WHO stage 3 or 4 event, of not having a CD4 ${ }^{+} \mathrm{T}$ cell count below $200 / \mathrm{mm}^{3}$, and of remaining free of all three outcomes were estimated at 0.92 (95\% CI 0.84-0.95), 0.81 (95\% CI 0.71-0.86), 0.64 (95\% CI 0.53-0.72) and 0.56 (95\% CI 0.46$0.65)$, respectively.

Figure 2 shows the probability of remaining free of all three outcomes over time, depending on baseline PBMC HIV-1 DNA level (2A), baseline CD4 count (2B), and baseline plasma HIV-1 RNA level (2C). The five-year probability of remaining free of any outcome was 0.74 in patients with baseline HIV-1 DNA $\leq 3.0 \log _{10}$ copies $/ 10^{6}$ PBMCs and 0.35 in patients with baseline DNA $>3.0 \log _{10}$ copies $/ 10^{6}$ PBMCs $(\mathrm{p}<0.001)$ (Figure $\left.2 \mathrm{~A}\right) ; 0.64$ in patients with baseline CD4 count $>350 / \mathrm{mm}^{3}$ and 0.31 in those with baseline CD4 count $\leq 350 / \mathrm{mm}^{3}(\mathrm{p}<0.001)$ (Figure $2 \mathrm{~B}$ ); and 0.61 in patients with baseline plasma HIV-1 RNA $\leq 5.0 \log _{10}$ copies/ml and 0.36 in those with HIV-1 RNA $>5.0 \log _{10}$ copies $/ \mathrm{ml}(\mathrm{p}=0.055)$ (Figure $\left.2 \mathrm{C}\right)$.

Table 2 shows the results of the multivariate analysis on the association between disease progression and patient characteristics, both for each outcome separately and for all outcomes combined. Patients with baseline HIV-1 DNA levels $>3 \log _{10}$ copies $/ 10^{6}$ PBMCs were 6.97 times more likely to die, 2.35 times more likely to attain a $\mathrm{CD} 4^{+} \mathrm{T}$-cell count $<200 / \mathrm{mm}^{3}$ and 2.17 times more likely to reach any of the three outcomes than patients with lower HIV-1 DNA levels. The HIV-1 DNA level had the strongest independent association with all outcomes. Follow-up CD4 T-cell counts were also associated with the combined outcomes, but the association was weaker. Interestingly, plasma HIV-1 RNA levels were weakly associated with outcomes after controlling for HIV-1 DNA level. 


\section{Discussion}

Within this cohort of West African adults who seroconverted to HIV-1 a median of 9 months before enrolment, baseline HIV-1 DNA level in PBMCs was strongly associated with HIV-1 disease progression, independently of plasma viral load and $\mathrm{CD} 4^{+}$T-cell count. Patients with baseline HIV-1 DNA level $>3 \log _{10}$ copies $/ 10^{6}$ PBMCs had a 7.0 increase in risk of death and a 2.4 increase in risk of $\mathrm{CD} 4^{+} \mathrm{T}$-cell count decline to $<200 / \mathrm{mm}^{3}$, compared to patients with HIV-1 DNA $<3 \log _{10}$ copies $/ 10^{6}$ PBMCs, after adjusting for other characteristics.

A similar independent association between early PBMC HIV-1 DNA level and HIV-1 disease progression has been reported elsewhere for European patients infected with sub-type B HIV-1 viruses (5-7). Our study demonstrates that these findings can be replicated in African adults harboring different HIV-1 subtypes and immunological and virologic characteristics. Compared to subjects in the European studies, our patients had higher baseline PBMC HIV-1 DNA levels and lower baseline $\mathrm{CD} 4^{+} \mathrm{T}$-cell counts (15). In addition, all were infected with non-B HIV-1 strains, mainly CRF02_AG (16-19). Despite these differences, our results are consistent with previous studies, showing the same large relative risk of progression for patients with high HIV-1 DNA levels, the same robustness in the results when using separate or combined progression outcomes, and the same overwhelming prognostic importance of HIV-1 DNA over plasma HIV1 RNA. In fact, the association of HIV-1 RNA with progression outcomes was not significant after adjusting for DNA levels.

In our study, $31 \%$ of participants started ART before the study ended. Some subjects started ART before having reached one or several criteria used to define disease progression. Time at risk was censored at ART initiation in these patients. This may have led to an informative bias, assuming that the progression of HIV-1 disease could have been different in these patients if they hadn't start ART, as compared with the progression of patients who didn't start ART. This bias would lead to underestimate disease progression more deeply for subjects whose baseline HIV-1 DNA level was $>3 \log _{10}$ copies $/ 10^{6}$ PBMCs, since a larger proportion of patients with high HIV-1 DNA levels started ART. Therefore, we may have underestimated the hazard ratio of disease progression in patients with high baseline HIV-1 DNA levels, relative to patients with low baseline HIV-1 DNA.

PBMC HIV-1 DNA may reflect the cellular reservoir of HIV-1, as opposed to plasma HIV-1 RNA that reflects HIV-1 replication (20). The strong association between baseline PBMC HIV-1 DNA and disease progression may reflect the prognostic importance of the number of HIV-1 
infected cells during acute infection. $\mathrm{CD}^{+}$T-cell counts and plasma HIV RNA levels have proven reliable and consistent markers, and are currently major indicators in the clinical standard of care. However, HIV-1 DNA levels could act as an additional marker to help distinguish those among patients with similar CD4 counts who might benefit from different therapeutic decisions. In our study, HIV-1 DNA levels were strongly associated with disease progression, even after adjusting for time-updated $\mathrm{CD} 4^{+}$T-cell counts. This suggests that HIV-1 DNA levels could help identify individuals at risk of disease progression within a specific CD4 stratum, thereby informing decisions to start antiretroviral therapy earlier in selected individuals. Further trials of early ART initiation should measure participants' PBMC HIV-1 DNA in order to address this question. 


\section{References}

1. Mellors JW, Munoz A, Giorgi JV, Margolick JB, Tassoni CJ, Gupta P, et al. Plasma viral load and CD4+ lymphocytes as prognostic markers of HIV-1 infection. Ann Intern Med 1997;126(12):946-54

2. Mellors J, Rinaldo CJ, Gupta P, White R, Todd J, Kingsley L. Prognosis in HIV-1 infection predicted by the quantity of virus in plasma. Science 1996;272:1167-70.

3. Hammer S, Squires K, Hughes M, Grimes J, Demeter L, Currier J, et al. A controlled trial of two nucleoside analogues plus indinavir in persons with human immunodeficiency virus infection and CD4 cell counts of 200 per cubic millimeter or less. AIDS Clinical Trials Group 320 Study Team. N Engl J Med 1997;337:725-33.

4. Gulick R, Mellors J, Havlir D, Eron J, Gonzalez C, McMahon D, et al. Treatment with indinavir, zidovudine, and lamivudine in adults with human immunodeficiency virus infection and prior antiretroviral therapy. N Engl J Med 1997;337:734-9.

5. Kostrikis L, Touloumi G, Karanicolas R, Pantazis N, Anastassopoulou C, Karafoulidou A, et al. Quantitation of human immunodeficiency virus type 1 DNA forms with the second template switch in peripheral blood cells predicts disease progression independently of plasma RNA load. J Virol 2002;76:10099-108.

6. Rouzioux C, Hubert J, Burgard M, Deveau C, Goujard C, Bary M, et al. Early levels of HIV-1 DNA in peripheral blood mononuclear cells are predictive of disease progression independently of HIV-1 RNA levels and CD4+ T cell counts. J Infect Dis 2005;192:4655

7. Goujard C, Bonarek M, Meyer L, Bonnet F, Chaix M, Deveau C, et al. CD4 cell count and HIV DNA level are independent predictors of disease progression after primary HIV type 1 infection in untreated patients. Clin Infect Dis 2006;42:709-15.

8. Salamon R, Marimoutou C, Ekra D, Minga A, Nerrienet E, Huet C, et al. Clinical and biological evolution of HIV-1 seroconverters in Abidjan, Cote d'Ivoire, 1997-2000. J Acquir Immune Defic Syndr 2002;29:149-157. 
9. Minga A, Danel C, Abo Y, Dohoun L, Bonard D, Coulibaly A, et al. Progression to WHO criteria for antiretroviral therapy in a 7-year cohort of adult HIV-1 seroconverters in Abidjan, Côte d'Ivoire. Bull World Health Organ 2007;85:116-123.

10. Anglaret X, Messou E, Ouassa T, Toure S, Dakoury-Dogbo N, Combe P, et al. Pattern of bacterial diseases in a cohort of HIV-1 infected adults receiving cotrimoxazole prophylaxis in Abidjan, Côte d'Ivoire. AIDS 2003;17:575-84.

11. Mermin J, Lule J, Ekwaru J, Malamba S, Downing R, Ransom R, et al. Effect of cotrimoxazole prophylaxis on morbidity, mortality, CD4-cell count, and viral load in HIV infection in rural Uganda. Lancet 2004;364:1428-34.

12. WHO. Scaling up antiretroviral therapy in resource-limited settings: Treatment guidelines for a public health approach. 2003 [cited 200415 juin 2004]; Available from:

13. WHO. Antiretroviral therapy for HIV infection in adults and adolescents in resourcelimited settings: towards universal access: recommendations for a public health approach (2006 revision). 2006; Available at:

http://www.who.int/hiv/pub/guidelines/WHO\%20Adult\%20ART\%20Guidelines.pdf

14. Schvachsa N, Turk G, Burgard M, Dilernia D, Carobene M, Pippo M, et al. Examination of real-time PCR for HIV-1 RNA and DNA quantitation in patients infected with HIV-1 BF intersubtype recombinant variants. J Virol Methods. 2007;140:222-7.

15. Lewden C, Thiebaut R, Boufassa F, Grondin C, Coulibaly A, Seng R, et al. Comparison in Early CD4 T Cell Count Evolution in HIV-1 Seroconverters in Côte d'Ivoire and France: The ANRS PRIMO-CI and SEROCO Cohorts. 15th conference on Retroviruses and Opportunistic Infections (CROI), Boston, MA, USA, February 3-6, 2008. Abstract 691.

16. Toni TD, Adje-Toure C, Vidal N, Minga A, Huet C, Borger M., et al. Presence of CRF09_cpx and Complex CRF02_AG/CRF09_cpx Recombinant HIV Type 1 Strains in Côte d'Ivoire, West Africa. AIDS Res Hum Retroviruses 2005;21:667-672.

17. Toni T, Recordon-Pinson P, Minga A, Ekouevi D, Bonard D, Bequet L, et al. Presence of key drug resistance mutations in isolates from untreated patients of Abidjan, Cote d'Ivoire: ANRS 1257 study. AIDS Res Hum Retroviruses 2003;9:713-717. 
18. Toni T, Masquelier B, Bonard D, Faure M, Huet C, Caumont A, et al. Primary HIV-1 drug resistance in Abidjan (Cote d'Ivoire): a genotypic and phenotypic study. Aids 2002;16(3):488-91

19. Toni T, Masquelier B, Minga A, Anglaret X, Danel C, Coulibaly A, et al. HIV-1 Antiretroviral Drug Resistance in Recently Infected Patients in Abidjan, Côte d'Ivoire: A 4-Year Survey, 2002-2006. AIDS Res Hum Retroviruses. 2007;23:1155-1160.

20. Cao Y, Qin L, Zhang L, Safrit J, Ho D. Virologic and immunologic characterization of long-term survivors of human immunodeficiency virus type 1 infection. N Engl J Med $1995 ; 332: 201-8$. 
Table 1: Baseline and follow-up patient characteristics $(n=200)$

Men, number (\%)

Age, years, median (IQR)

Time from seroconversion, months, median (IQR)

CD4 cell count $/ \mathrm{mm}^{3}$, median (IQR)

$$
\leq 200 / \mathrm{mm}^{3} \text {, number }(\%)
$$

CD4 cell percentage, median (IQR)

$$
\leq 10 \% \text {, number }(\%)
$$

HIV-1 RNA, $\log _{10}$ copies/ml, median (IQR)

HIV-1 DNA, $\log _{10}$ copies $/ 10^{6} \mathrm{PBMC}$, median (IQR)

Haemoglobin, g/L, median (IQR)

Positive serum HBs antigen, number (\%)

Body Mass Index, $\mathrm{kg} / \mathrm{m}^{2}$, median (IQR)

\section{Status at study termination, n (\%)}

Off HAART

Dead

Lost to follow-up *

Alive

On HAART

Dead

Lost to follow-up

Alive

Cumulative follow-up, in person-years
123

29

$(62 \%)$

471

14

25

5

4. 6

3.0

123

9

22.1

(20.3-24.6)

138

$(69 \%)$

47

604

30

(15-51)

Follow-up, in months, median (IQR)

IQR : Interquartile Range ; PBMCs : peripheral blood mononuclear cells ;

* patients whose last contact with study team was before the date of study termination and who could not be traced six months after study termination 


\begin{tabular}{|c|c|c|c|c|c|c|}
\hline & \multicolumn{3}{|c|}{ Univariate analysis } & \multicolumn{3}{|c|}{ Multivariate analysis } \\
\hline & HR & $95 \% \mathrm{CI}$ & $p$ & $\mathrm{HR}$ & $95 \% \mathrm{CI}_{\%}$ & $p$ \\
\hline \multicolumn{7}{|l|}{ Death (10 events) } \\
\hline Women & 0.48 & $0.10-2.22$ & 0.35 & - & - & - \\
\hline Age $>25$ years & 2.05 & $0.44-9.40$ & 0.35 & - & - & - \\
\hline $\mathrm{BMI}>20.5 \mathrm{~kg} / \mathrm{m}^{2}$ & 0.74 & $0.22-2.47$ & 0.63 & - & - & - \\
\hline Time since seroconversion $>9$ months & 2.31 & $0.69-7.67$ & 0.17 & 2.63 & $0.74-9.38$ & 0.13 \\
\hline $\mathrm{CD} 4 / \mathrm{mm}^{3}$ (continous variable) ${ }^{*}$ & 1.23 & $0.93-1.64$ & 0.15 & 1.01 & $0.74-1.38$ & 0.93 \\
\hline Haemoglobin $<110 \mathrm{~g} / \mathrm{L}$ & 3.55 & $1.11-11.28$ & 0.03 & 6.00 & $1.57-22.94$ & 0.009 \\
\hline HIV-1 DNA > $3 \log _{10}$ copies $* *$ & 7.90 & $1.69-36.83$ & 0.008 & 6.97 & $1.26-38.73$ & 0.03 \\
\hline HIV-1 RNA > $5 \log _{10}$ copies $* * *$ & 3.54 & $1.11-11.26$ & 0.03 & 2.87 & $0.79-10.43$ & 0.11 \\
\hline \multicolumn{7}{|l|}{ First CD4 $<200 / \mathrm{mm}^{3}$ (41 events) } \\
\hline Women & 0.96 & $0.51-1.79$ & 0.90 & - & - & - \\
\hline Age $>25$ years & 0.80 & $0.44-1.45$ & 0.47 & - & - & - \\
\hline $\mathrm{BMI}>20.5 \mathrm{~kg} / \mathrm{m}^{2}$ & 1.19 & $0.62-2.28$ & 0.59 & - & - & - \\
\hline Time since seroconversion $>9$ months & 1.32 & $0.75-2.33$ & 0.32 & - & - & - \\
\hline $\mathrm{CD} 4 / \mathrm{mm}^{3}$ (continous variable)* & 1.30 & $1.12-1.49$ & $<0.001$ & 1.28 & $1.09-1.50$ & 0.003 \\
\hline Haemoglobin $<110 \mathrm{~g} / \mathrm{L}$ & 0.88 & $0.39-1.96$ & 0.75 & - & - & - \\
\hline HIV-1 DNA > $3 \log _{10}$ copies $* *$ & 3.39 & $1.86-6.20$ & $<0.001$ & 2.35 & $1.22-4.52$ & 0.01 \\
\hline HIV-1 RNA > $5 \log _{10}$ copies $* * *$ & 2.35 & $1.20-4.59$ & 0.01 & 1.74 & $0.86-3.51$ & 0.12 \\
\hline \multicolumn{7}{|l|}{ First stage 3 or 4 event ( 25 events) } \\
\hline Women & 0.79 & $0.33-1.91$ & 0.61 & - & - & - \\
\hline Age $>25$ years & 1.24 & $0.50-3.11$ & 0.65 & - & - & - \\
\hline $\mathrm{BMI}>20.5 \mathrm{~kg} / \mathrm{m}^{2}$ & 0.96 & $0.40-2.29$ & 0.92 & - & - & - \\
\hline Time since seroconversion $>9$ months & 2.04 & $090-4.61$ & 0.08 & 1.88 & $0.80-4.41$ & 0.14 \\
\hline $\mathrm{CD} 4 / \mathrm{mm}^{3}$ (continous variable) ${ }^{*}$ & 1.21 & $0.99-1.48$ & 0.06 & 1.09 & $0.88-1.35$ & 0.41 \\
\hline Haemoglobin $<110 \mathrm{~g} / \mathrm{L}$ & 1.80 & $0.75-4.33$ & 0.19 & 1.79 & $0.73-4.35$ & 0.20 \\
\hline HIV-1 DNA > $3 \log _{10}$ copies $* *$ & 2.23 & $0.98-5.06$ & 0.05 & 1.94 & $0.81-4.66$ & 0.14 \\
\hline HIV-1 RNA > $5 \log _{10}$ copies $* * *$ & 1.29 & $0.51-3.23$ & 0.60 & - & - & - \\
\hline \multicolumn{7}{|l|}{ Any of the three outcomes (57 events) } \\
\hline Women & 0.96 & $0.56-1.64$ & 0.88 & - & - & - \\
\hline Age $>25$ years & 0.96 & $0.57-1.63$ & 0.88 & - & - & - \\
\hline $\mathrm{BMI}>20.5 \mathrm{~kg} / \mathrm{m}^{2}$ & 1.23 & $0.70-2.17$ & 0.47 & - & - & - \\
\hline Time since seroconversion $>9$ months & 1.35 & $0.83-2.20$ & 0.22 & 1.22 & $0.73-2.04$ & 0.44 \\
\hline $\mathrm{CD} 4 / \mathrm{mm}^{3}$ (continous variable) ${ }^{*}$ & 1.27 & $1.12-1.44$ & $<0.0001$ & 1.23 & $1.07-1.41$ & 0.003 \\
\hline Haemoglobin $<110 \mathrm{~g} / \mathrm{L}$ & 1.33 & $0.73-2.40$ & 0.35 & - & - & - \\
\hline HIV-1 DNA > $3 \log _{10}$ copies $* *$ & 2.84 & $1.70-4.73$ & $<0.0001$ & 2.17 & $1.24-3.80$ & 0.007 \\
\hline HIV-1 RNA > $5 \log _{10}$ copies $* * *$ & 1.76 & $0.98-3.18$ & 0.06 & 1.24 & $0.67-2.31$ & 0.50 \\
\hline
\end{tabular}

BMI : Body Mass Index ; HR: Hazard Ration ; CI: confidence interval ; g/L: gram per liter

* CD4 count was included in the analysis as a time-dependant variable and was analysed for each decrease of 100 cells $/ \mathrm{mm}^{3}$.

** per $10^{6} \mathrm{PBMCs}$

$* * *$ per $\mathrm{ml}$ 
Figure 1: Probability of remaining free of any outcome (death, first WHO clinical stage 3-4 defining disease, or first CD4 below $200 / \mathrm{mm}^{3}$ ) over time

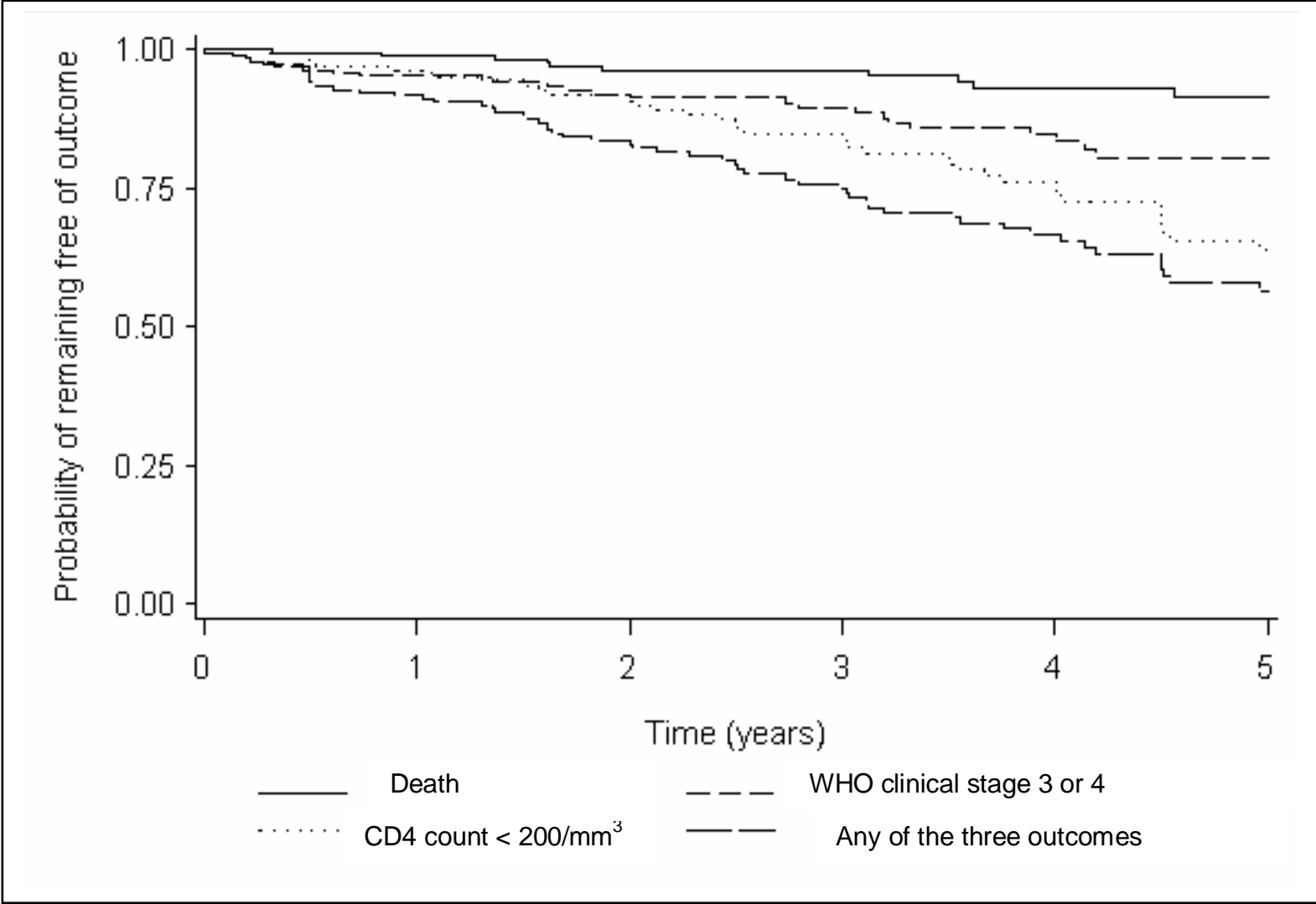

1 year

2 years

3 years

4 years

5 years

\section{Death}

$\begin{array}{lccccc}\text { ARP } & 177 & 134 & 106 & 76 & 48 \\ \mathrm{n} & 2 & 6 & 6 & 9 & 10 \\ \text { Probability } & 0.99 & 0.96 & 0.96 & 0.93 & 0.92 \\ (95 \% \mathrm{Cl}) & (0.96-0.99) & (0.92-0.98) & (0.92-0.98) & (0.87-0.97) & (0.84-0.96)\end{array}$

WHO clinical stage 3 or 4

$\begin{array}{lccccc}\text { ARP } & 171 & 128 & 100 & 69 & 41 \\ \mathrm{n} & 9 & 15 & 17 & 22 & 25 \\ \text { Probability } & 0.95 & 0.91 & 0.90 & 0.85 & 0.81 \\ (95 \% \mathrm{Cl}) & (0.91-0.98) & (0.86-0.95) & (0.84-0.93) & (0.77-0.90) & (0.72-0.87)\end{array}$

\section{CD4 count $<200 / \mathrm{mm}^{3}$}

ARP

$\mathrm{n}$

Probability

$(95 \% \mathrm{Cl})$

Any outcome

\begin{tabular}{lccccc} 
ARP & 169 & 120 & 88 & 62 & 37 \\
$\mathrm{n}$ & 16 & 30 & 40 & 49 & 57 \\
Probability & 0.92 & 0.83 & 0.75 & 0.67 & 0.56 \\
$(95 \% \mathrm{Cl})$ & $(0.87-0.95)$ & $(0.76-0.88)$ & $(0.67-0.81)$ & $(0.58-0.74)$ & $(0.46-0.65)$ \\
\hline
\end{tabular}

ARP: at-risk patients ; n: number of patients who reached the outcome ; Cl: confidence interval 
Figure 2 -A: Probability of remaining free of any outcome (death, first WHO clinical

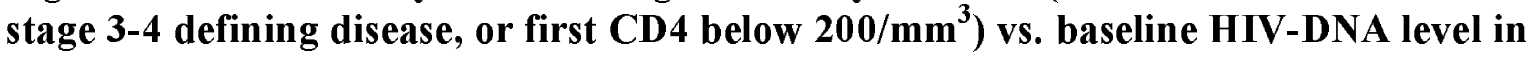
PBMCs

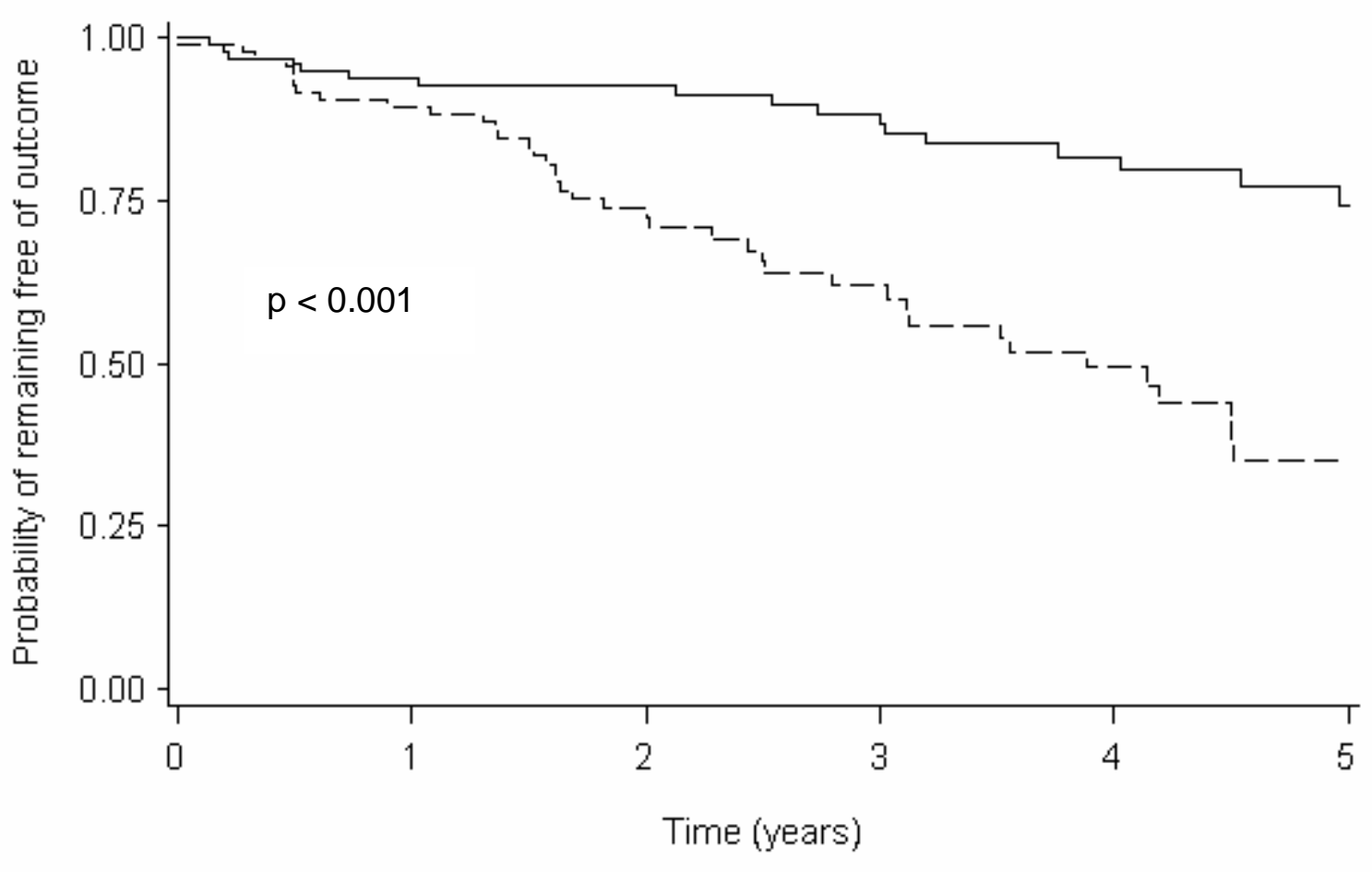

HIV-DNA $\leq 3 \log _{10}$ copies $/ 10^{6}$ PBMC

- HIV-DNA > $3 \log _{10}$ copies $/ 10^{6}$ PBMC

1 year 2 years 3 years 4 years 5 years

HIV-1 DNA $\leq 3 \log 10$ copies $/ 10^{6}$ PBMCs

$\begin{array}{lccccc}\text { ARP } & 90 & 71 & 57 & 41 & 25 \\ \mathrm{n} & 6 & 7 & 11 & 14 & 17 \\ \text { Probability } & 0.94 & 0.93 & 0.87 & 0.82 & 0.74 \\ (95 \% \mathrm{Cl}) & (0.87-0.97) & (0.86-0.97) & (0.77-0.93) & (0.71-0.89) & (0.60-0.84)\end{array}$

HIV-1 DNA > $3 \log 10$ copies $/ 10^{6}$ PBMCs

\begin{tabular}{lccccc} 
ARP & 79 & 49 & 31 & 21 & 12 \\
$\mathrm{n}$ & 10 & 23 & 29 & 35 & 40 \\
Probability & 0.89 & 0.72 & 0.62 & 0.49 & 0.35 \\
$(95 \% \mathrm{Cl})$ & $(0.81-0.94)$ & $(0.61-0.81)$ & $(0.49-0.72)$ & $(0.36-0.61)$ & $(0.22-0.49)$ \\
\hline
\end{tabular}

ARP: at-risk patients ; $\mathrm{n}$ : number of patients who reached the outcome ; Cl: confidence interval 
Figure 2 -B: Probability of remaining free of any outcome (death, first WHO clinical stage 3-4 defining disease, or first CD4 below $200 / \mathrm{mm}^{3}$ ) vs. baseline CD4 count

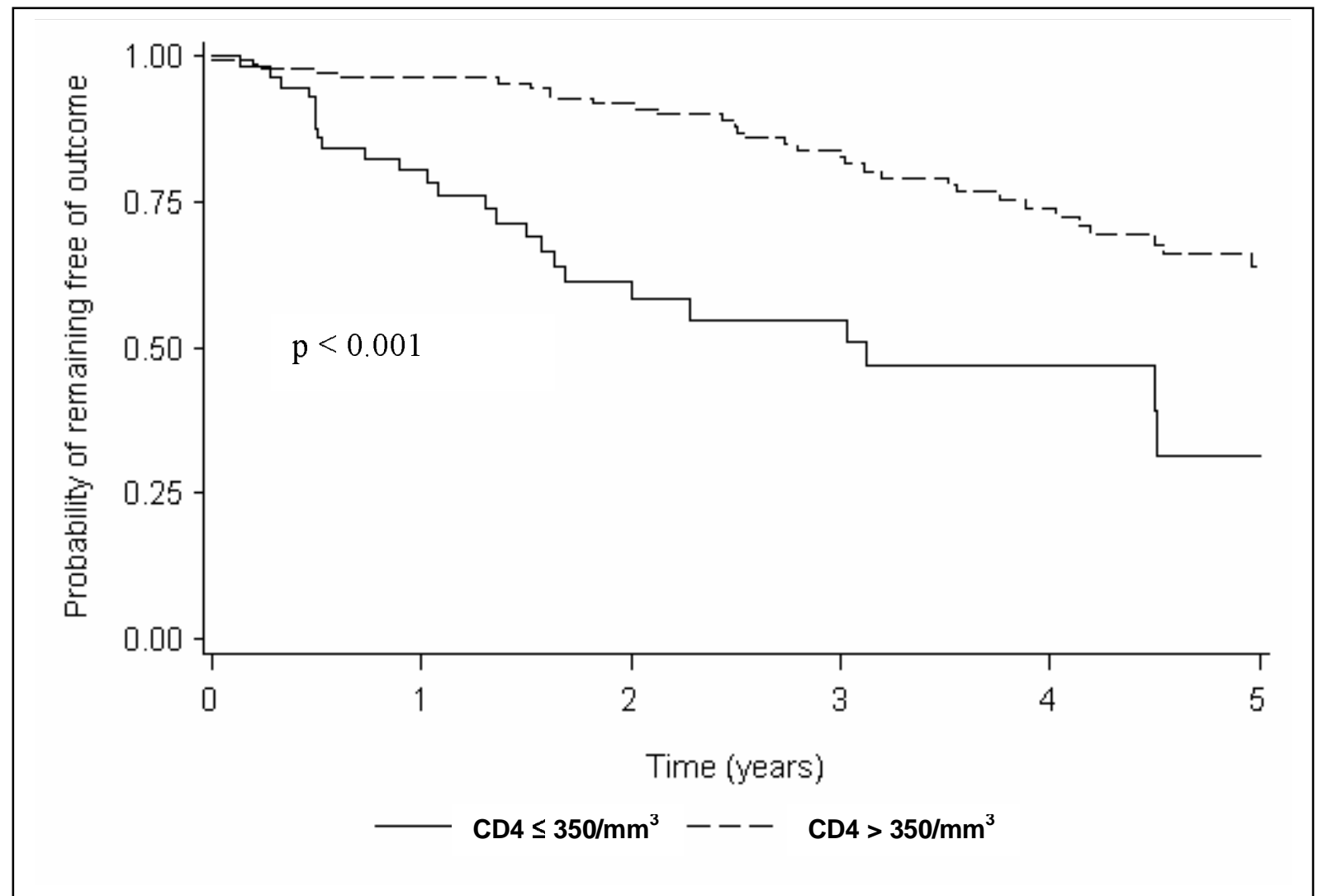

\begin{tabular}{lccccc}
\hline & 1 year & 2 years & 3 years & 4 years & 5 years \\
CD4 $>\mathbf{3 5 0} / \mathbf{m m}^{3}$ & & & & & \\
ARP & 129 & 101 & 74 & 52 & 33 \\
$\mathrm{n}$ & 5 & 10 & 19 & 26 & 32 \\
Probability & 0.96 & 0.92 & 0.83 & 0.74 & 0.64 \\
$\quad(95 \% \mathrm{Cl})$ & $(0.91-0.98)$ & $(0.86-0.96)$ & $(0.74-0.89)$ & $(0.64-0.82)$ & $(0.52-0.74)$ \\
CD4 $\leq 350 / \mathbf{m m}^{3}$ & & & & & \\
ARP & 40 & 19 & 14 & 10 & 4 \\
$\mathrm{n}$ & 11 & 20 & 21 & 23 & 25 \\
Probability & 0.81 & 0.58 & 0.55 & 0.47 & 0.31 \\
$(95 \% \mathrm{Cl})$ & $(0.68-0.89)$ & $(0.42-0.71)$ & $(0.39-0.69)$ & $(0.30-0.62)$ & $(0.13-0.52)$ \\
\hline
\end{tabular}

ARP: at-risk patients ; n: number of patients who reached the outcome ; Cl: confidence interval 
Figure 2 -C: Probability of remaining free of any outcome (death, first WHO clinical stage 3-4 defining disease, or first CD4 below $200 / \mathrm{mm}^{3}$ ) vs. baseline plasma HIV-1 RNA level

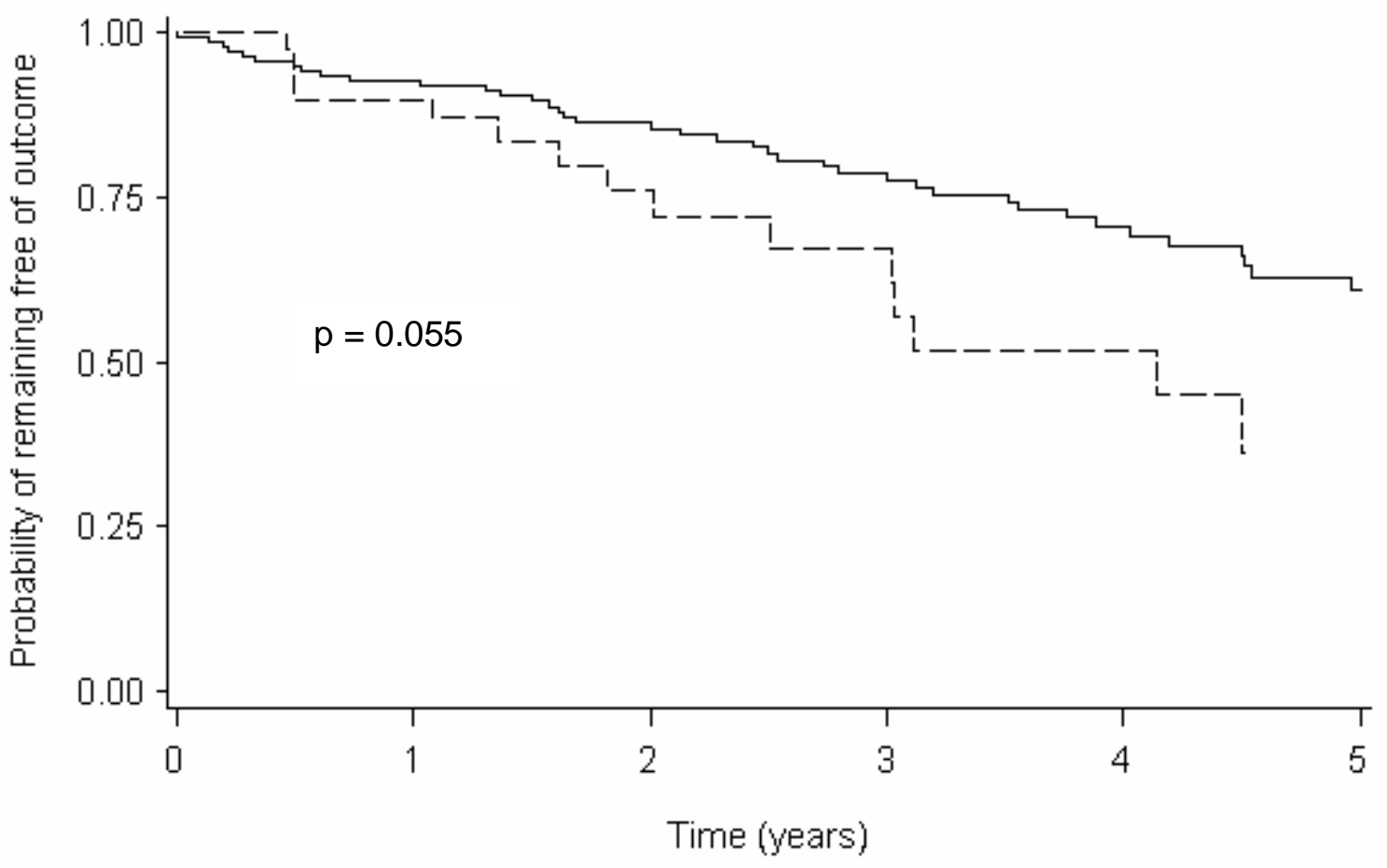

HIV-RNA $\leq 5 \log _{10}$ copies $/ \mathrm{ml} \quad-\quad-\quad$ HIV-RNA $>5 \log _{10}$ copies $/ \mathrm{ml}$

1 year 2 years 3 years 4 years 5 years

HIV-1 RNA $\leq 5 \log _{10}$ copies/ml

$\begin{array}{lccccc}\text { ARP } & 124 & 99 & 75 & 54 & 34 \\ \mathrm{n} & 10 & 19 & 27 & 33 & 39 \\ \text { Probability } & 0.93 & 0.86 & 0.78 & 0.71 & 0.61 \\ (95 \% \mathrm{Cl}) & (0.87-0.96) & (0.78-0.90) & (0.69-0.84) & (0.61-0.78) & (0.50-0.71)\end{array}$

HIV-1 RNA > 5 $\log _{10}$ copies $/ \mathrm{ml}$

\begin{tabular}{lccccc} 
ARP & 32 & 19 & 13 & 8 & 3 \\
$\mathrm{n}$ & 4 & 8 & 10 & 13 & 15 \\
Probability & 0.90 & 0.76 & 0.67 & 0.52 & 0.36 \\
$(95 \% \mathrm{Cl})$ & $(0.75-0.96)$ & $(0.57-0.87)$ & $(0.46-0.81)$ & $(0.30-0.69)$ & $(0.15-0.58)$ \\
\hline
\end{tabular}

ARP: at-risk patients ; n: number of patients who reached the outcome ; Cl: confidence interval 